\title{
Conceitos e relações entre educação inclusiva e educação especial nas legislações educacionais do Brasil, Santa Catarina e Blumenau
}

\author{
Juliany Mazera Fraga* \\ Aline Martins Varela** \\ Andrea Soares Wuo*** \\ Rita Buzzi Rausch ${ }^{* * * *}$
}

\section{Resumo}

Esta pesquisa teve por finalidade analisar os conceitos e as relaçôes estabelecidas entre educação especial e educação inclusiva nas políticas educacionais em esfera nacional, em Santa Catarina e de Blumenau. Considera-se que a compreensão de tais conceitos é necessária para a superação das dicotomias, historicamente construídas, entre educação regular e educação especial que dificultam o estabelecimento de uma perspectiva de educação inclusiva que garanta, nos diversos espaços e tempos escolares, uma educação de qualidade para todas as pessoas. Trata-se de uma pesquisa qualitativa em que foram analisados documentos oficiais produzidos entre os anos de 2008 e 2012, a saber: a Política Nacional de Educação Especial na Perspectiva da Educação Inclusiva (2008), o Programa Pedagógico da Fundação Catarinense de Educação Especial - FCEE (2009), a Política de Educação Especial do Estado de Santa Catarina (2009) e as Diretrizes Curriculares Municipais para a Educação Básica de Blumenau (2012). Os resultados indicam que, de acordo com os documentos analisados, a educação especial tende a assumir um caráter transversal e dialógico em relação ao sistema educacional como um todo e garantir a entrada, permanência, aprendizagem e participação das pessoas com necessidades educacionais especiais, por meio dos serviços de Atendimento Educacional Especializado. Por outro lado, notam-se particularidades das políticas estadual e municipal, sobretudo em relação aos serviços oferecidos e público atendido. Como conclusão, constatou-se que a educação inclusiva é uma perspectiva para a atuação na educação especial, cujo objetivo é incluir os estudantes com deficiência na escola regular.

Palavras-chave: Educação Especial; Educação inclusiva; Políticas educacionais.

\footnotetext{
* Mestranda em Educação pela Universidade Regional de Blumenau, Blumenau, Santa Catarina, Brasil.

** Mestranda em Educação pela Universidade Regional de Blumenau, Blumenau, Santa Catarina, Brasil.

*** Professora Doutora da Universidade Regional de Blumenau, Blumenau, Santa Catarina, Brasil.

**** Professora Doutora da Universidade Regional de Blumenau, Blumenau, Santa Catarina, Brasil.
} 


\section{Concepts and relationships between the inclusive education and the special education in the educa- tional legislation in brazil, santa catarina and blu- menau}

\section{Abstract}

This research aimed to analyze the concepts and the relationships established between the special education and the inclusive education in the educational policies in Brazil, Santa Catarina and Blumenau. It is considered that the understanding about the concepts is necessary to overcome the dichotomies, built historically, between the regular education and the special education that hamper the establishment of an inclusive education perspective that ensure, in the different school spaces and times, an education with quality for all the people. It is a qualitative research in wich were analyzed oficial documents produced between 2008 and 2012. They are: the National Special Education Policy from the Inclusive Education Perspective (2008), the Pedagogical Program of the Catarinense Special Education Foundation - CSEF (2009), the Special Education Policy of the Santa Catarina State (2009) and the National Curriculum Directives for Basic Education in Blumenau (2012). The results indicate that the special education tends to assume a transverse and a dialogic character about the educational system as a whole and to ensure the entry, permanence, learning and participation of peoples with special educacional needs, through the Specialized Educational Services. On the other hand, it noticed some particularities of the state and municipal policies, especially in relation to the services offered and the public served. As a conclusion, it was noted that the inclusive education is a perscpective to act in the special education, however the special education aims to include the students with some disability in the regular school causing the inclusion process.

Keywords: Special education; Inclusive education; Educational policies.

\section{Introdução}

Muitos são os questionamentos quando se trata dos conceitos relativos à educação inclusiva e à educação especial. O que é educação inclusiva? O que é educação especial? Quais são as relaçóes entre os dois conceitos?

No intuito de discutir tais questóes, a presente pesquisa teve por objetivo analisar os conceitos e as relaçóes estabelecidas entre educaçáo especial e educação inclusiva nas políticas educacionais em esfera nacional, em Santa Catarina e de Blumenau. Com o propósito de contextualizar a história da educação especial, fez-se um breve retrospecto no que diz respeito às datas que serviram de marco na política pública especial brasileira em uma perspectiva inclusiva.

Até a década de 1970 pouco se ouvia falar sobre as crianças com deficiência na escola comum, pois elas encontravam-se fora do sistema educacional, frequentando escolas ou classes especiais. Com a lei no 5.692, de 11 de agosto de 1971 que tem 
por objetivo em seu Artigo $9^{\circ}$ proporcionar aos educandos com deficiência mental e física tratamento especial, fica definido quem são os alunos da educação especial, sendo estes: deficientes físicos ou "mentais", alunos com atraso em relação à idade e à matrícula no ensino regular e os superdotados (MENDES, 2010).

A década de 1990 foi marcada pela reafirmação dos princípios educacionais oriundos da Conferência Mundial de Educação para Todos (1990) e da Declaração de Salamanca (1994), no intuito de garantir a todas as pessoas com necessidades educacionais especiais (NEE) o direito à educação de qualidade.

A partir dos anos 2000, o Brasil cria leis mais específicas para tratar de assuntos referentes à temática, representando significativos avanços das políticas educacionais. Foi a partir das Diretrizes Nacionais que se afirmou a perspectiva inclusiva adotada pelas políticas de Educação Especial no Brasil, destacando-se: Política Nacional de Educação Especial na Perspectiva da Educação Inclusiva (2008); Decreto No 6.571/2008 - Dispóe sobre o Atendimento Educacional Especializado; Convenção sobre os Direitos das Pessoas com Deficiência/ONU - Ratificada pelo Decreto No 6.949/2009; Diretrizes Operacionais para o Atendimento Educacional Especializado na Educação Básica - Modalidade Educação Especial, Resolução - No 4 CNE/CEB 2009, e a Lei No 13.146, de 6 de julho de 2015, a lei brasileira de inclusão da pessoa com deficiência (estatuto da pessoa com deficiência) que entrou em vigor em janeiro de 2016.

Com o objetivo de analisar os conceitos e as relaçôes estabelecidas entre educação especial e educação inclusiva nas políticas educacionais em esfera nacional, em Santa Catarina e Blumenau, realizou-se uma pesquisa documental de abordagem qualitativa, sendo selecionados os seguintes documentos: a Política Nacional de Educação Especial na Perspectiva da Educação Inclusiva (2008), o Programa Pedagógico da Fundaçáo Catarinense de Educação Especial - FCEE (2009), a Política de Educaçáo Especial do Estado de Santa Catarina (2009) e as Diretrizes Curriculares Municipais para a Educação Básica de Blumenau (2012). A opção pela análise das políticas relativas ao estado de Santa Catarina e à cidade de Blumenau justifica-se pelo próprio contexto de pesquisa e a necessidade de investigação da realidade em que esta se insere.

\section{Educação inclusiva e especial nas políticas: nacional, es- tadual e municipal}

Nas seçôes que seguem serão abordadas as principais políticas de educação inclusiva e educação especial de acordo com os documentos nacionais, do estado de Santa Catarina e do município de Blumenau, trazendo definiçóes e uma breve discussão acerca da temática.

\section{Educação inclusiva nas políticas: nacional, estadual e municipal}

A educação especial já foi tratada como segregação, integração e atualmente como inclusão. Embora aparentemente semelhantes, essas nomenclaturas possuem significados distintos. Entende-se por "segregaçáo" o processo de dissociação segundo 
o qual os indivíduos acabam se afastando de outros indivíduos, baseando-se na convicção de que seriam melhor atendidos em ambientes separados às classes comuns. Já o termo "integração" foi mais utilizado nos países europeus e se tratava da inserção dos alunos com deficiências também em escolas comuns, porém em classes separadas. Partia-se do princípio que o aluno e sua família deveriam adaptar-se à escola, sem que esta oferecesse atenção especializada. A "inclusáo" ganhou maior visibilidade nos Estados Unidos, após a década de 1990, pois neste país utilizava-se do termo "inclusão escolar" para a inserção de alunos com necessidades educacionais especiais nas escolas comuns. (MENDES, 2006).

Percebe-se que o termo inclusão é mais amplo e abrangente, pois na inclusão "[...] não é o aluno que se adapta à escola, mas é ela que, consciente da sua função, coloca-se à disposiçẫo do aluno, tornando-se um espaço inclusivo." (BRASIL, 2001, p. 29) Desse modo, faz-se necessária uma reestruturação da escola como um todo, ou seja, ela e todos os seus membros devem estar preparados para acolher os estudantes com NEE, fazendo adaptaçôes necessárias garantindo seu processo de escolarização.

A Política Nacional de Educação Especial na Perspectiva da Educação Inclusiva (2008) conceitua a Educação Inclusiva como:

[...] um paradigma educacional fundamentado na concepção de direitos humanos, que conjuga igualdade e diferença como valores indissociáveis, e que avança em relação à idéia de eqüidade formal ao contextualizar as circunstâncias históricas da produção da exclusão dentro e fora da escola. (BRASIL, 2008, p. 5).

Partindo de tal afirmação, todos os alunos, independente de sua condição, são considerados sujeitos de direitos. No entanto, observa-se que, apesar da presença de leis que garantam a igualdade de oportunidades a todos, as relaçôes de estigma, baseadas em preconceitos, que se constroem entre alunos com deficiência, transtornos globais de desenvolvimento e altas habilidade/superdotação e a comunidade escolar ainda persistem, levando o estudante "estigmatizado" ao distanciamento e isolamento do grupo em que se insere, estabelecendo-se novas formas de exclusão dentro da própria dinâmica da inclusão. Conforme Sawaia (2001, p. 9):

[...] a exclusão é processo complexo e multifacetado, uma configuração de dimensões materiais, políticas, relacionais e subjetivas. É processo sutil e dialético, pois só existe em relaçáo à inclusão como parte constitutiva dela. Não é uma coisa ou um estado, é processo que envolve o homem por inteiro e suas relaçóes com os outros. (SAWAIA, 2001, p. 9).

A Política de Educação Especial do Estado de Santa Catarina considera que: "[...] a inclusão traz a diversidade como atributo essencial para o desenvolvimento humano, reconhece o outro como sujeito histórico e social, projeta mudanças de concepçōes e atitudes." (SANTA CATARINA, 2009, p. 9). Com isso, assegura-se a necessidade de transformação não apenas em âmbito didático-pedagógico, mas daquelas concepçóes socialmente construídas que limitam o olhar sobre a diferença, entendendo-a como obstáculo para a educação, e náo como oportunidade de de- 
senvolvimento. Diante disso, "deve haver a ampliação do atendimento educacional em escolas regulares públicas e a migração desta população dos espaços segregados, especialmente aqueles privados de caráter filantrópico, para os sistemas regulares de ensino." (MELETTI; RIBEIRO, 2014, p. 178).

O conceito de Educação Inclusiva no qual o município de Blumenau está fundamentado se reporta à Declaração de Salamanca, definindo-a como:

Princípio fundamental da escola inclusiva é o de que todas as crianças devem aprender juntas, sempre que possível, independentemente de quaisquer dificuldades ou diferenças que elas possam ter. Escolas inclusivas devem reconhecer e responder às necessidades diversas de seus alunos, acomodando ambos os estilos e ritmos de aprendizagem e assegurando uma educação de qualidade a todos através de um currículo apropriado, arranjos organizacionais, estratégias de ensino, uso de recurso e parceria com as comunidades. [...]. Educação inclusiva é o modo mais eficaz para construção de solidariedade entre crianças com necessidades educacionais especiais e seus colegas. (BLUMENAU, 1994, p. 5).

Desse modo, a educação inclusiva deve se preocupar com o acesso, permanência e aprendizagem dos alunos com NEE na escola regular, removendo barreiras e promovendo o processo de ensinar e aprender desses educandos, assim como a interação com os demais alunos.

\section{Educação especial nas políticas: nacional, estadual e municipal}

A Educação Especial na "perspectiva da educação inclusiva busca superar a visão do caráter substitutivo da Educação Especial ao ensino comum, bem como a organização de espaços educacionais separados para alunos com deficiência" (BRASIL, 2013, p. 160), ou seja, é uma educação voltada para atender as crianças e/ou estudantes que apresentam algum tipo de deficiência, transtornos globais de desenvolvimento e altas-habilidades/superdotação. Esse atendimento é realizado tanto em escolas especiais, quanto nas regulares, visando o contato desses com os demais alunos.

A Política Nacional de Educação Especial na Perspectiva da Educação Inclusiva (2008) conceitua a educação especial como sendo:

[...] uma modalidade de ensino que perpassa todos os níveis, etapas e modalidades, realiza o atendimento educacional especializado, disponibiliza os recursos e serviços e orienta quanto a sua utilizaçáo no processo de ensino e aprendizagem nas turmas comuns do ensino regular. (BRASIL, 2008, p. 11).

Portanto, a educação especial acontece em todas as etapas de escolarização do sujeito que dela necessita. É direito do estudante receber o AEE que deve ocorrer, preferencialmente, de forma integrada e transversal ao sistema regular de ensino e não separadamente:

A Educação Especial tradicionalmente se configurou como um sistema paralelo e segregado de ensino, voltado para o atendimento especializado de indivíduos com deficiências, distúrbios graves de 
aprendizagem e/ou de comportamento, e altas habilidades. Contudo, a partir das últimas décadas, em função de novas demandas e expectativas sociais, os profissionais da área têm se voltado para a busca de outras formas de educação escolar com alternativas menos segregativas de absorção desses educandos nas redes de ensino. (GLAT; PLETSCH; FONTES, 2007, p. 344).

Nesse sentido, a busca por novas estratégias de ensino que visem à inserção dos estudantes com NEE nas escolas regulares colabora com o desenvolvimento de uma perspectiva de "educação para todos", em que diversidade passa a ser vista não mais como um "problema" para o ensino regular, mas como condição para o seu exercício.

O Brasil conta com legislaçóes acerca da educação especial e seu atendimento nas escolas, explicando como e onde ele deve ser realizado. As Diretrizes Nacionais para a Educação Especial na Educação Básica (2001) define a educação especial como um:

\begin{abstract}
Processo educacional definido em uma proposta pedagógica assegurando um conjunto de recursos e serviços educacionais especiais, organizados institucionalmente para apoiar, suplementar, complementar e, em alguns casos, substituir os serviços educacionais comuns. (BRASIL, 2001, p. 27).
\end{abstract}

Diante disso, a escola regular deve ir adaptando recursos materiais e se preparando profissionalmente por meio da formação docente para receber de maneira adequada e acolhedora todos os sujeitos que necessitem da educação especializada, pois a educação especial pode ser "[...] concebida como um sistema educacional especializado à parte, [formando] um conjunto de metodologias, recursos e conhecimentos [...] que a escola comum deverá dispor para atender à diversidade de seu alunado.” (GLAT; PLETSCH; FONTES, 2007, p. 345)

A educação especial pressupóe a inclusão de todos os alunos com deficiências e outras NEEs ${ }^{1}$ junto aos demais estudantes da escola, desta forma, esses sujeitos terão acesso à educação, o que lhes proporcionará um ensino emancipador, gerando oportunidades iguais.

De acordo com a Política Nacional de Educação Especial na Perspectiva da Educação Inclusiva (2008, p. 11) a "educação especial atua de forma articulada com o ensino comum, orientando para o atendimento destes estudantes. [...] Esse atendimento complementa e/ou suplementa a formação dos estudantes com vistas à autonomia e independência na escola e fora dela." Estabelecer diálogos entre as duas esferas educacionais torna possível uma educação especial como parte integrante da educação regular, pois:

[...] em grande medida os modi operandi das salas de recursos, do ponto de vista do trabalho docente ali realizado, se mantêm como paralelo ao trabalho realizado na classe comum, o qual pouco incide sobre o processo de escolarizaçáo dos sujeitos da modalidade Educação Especial. (GARCIA, 2013, p. 109). 
Com o documento Política Nacional de Educação Especial na Perspectiva da Educaçãoo Inclusiva (2008), a educação especial torna-se transversal em relação à educação regular, assumindo uma ideia de educação comum a todos. Tal política delimitou o $\mathrm{AEE}$ como um processo de inclusão escolar e que este deve acontecer nas salas de recursos multifuncionais, proporcionando a matrícula destes estudantes tanto na educação básica quanto na educação especial. (HOSTINS; JORDÃO, 2014)

A Política Nacional de Educação Especial na Perspectiva da Educação Inclusiva (2008) diz que o AEE possui a funçáo de: "[...] identificar, elaborar e organizar recursos pedagógicos e de acessibilidade que eliminem as barreiras para a plena participação dos estudantes, considerando suas necessidades específicas. [...] não sendo substitutivas à escolarizaçáo." (BRASIL, 2008, p. 16) Segundo o documento, o atendimento deve acontecer como um apoio ao estudante com NEE, ou seja, ele deve ir à escola regular e no contra turno frequentar a sala de recurso multifuncional que funciona na escola em que estuda ou em outras unidades escolares. Mas "o que se observa é uma restrição das atividades da SRM [Sala de Recurso Multifuncional] ao suporte de recursos pedagógicos, uma individualização do ensino e um isolamento do trabalho". (HOSTINS; JORDÃO, 2014, p. 15)

No âmbito estadual de Santa Catarina os documentos norteadores da educação especial são a Política de Educação Especial do Estado de Santa Catarina (2009) e o Programa Pedagógico da Fundação Catarinense de Educação Especial (2009).

A Política de Educação Especial do Estado de Santa Catarina define a Educação Especial:

[...] como processo interdisciplinar que visa à prevenção, ao ensino e à reabilitação da pessoa com deficiência, condutas típicas e altas habilidades, objetivando sua inclusão mediante a utilizaçáo de recursos pedagógicos e tecnológicos específicos. Em âmbito educacional, como uma modalidade que perpassa todos os níveis, etapas e modalidades, organizada para apoiar, complementar e suplementar a aprendizagem dos educandos. (SANTA CATARINA, 2009, p. 22)

Portanto, segundo o documento estadual, a educação especial deve se fazer presente durante todo o processo inclusivo, proporcionando ao estudante com NEE no ensino regular a interdisciplinaridade no que se refere ao envolvimento de diversos profissionais e etapas que perpassam seu processo inclusivo, contando com materiais didáticos e uma prática pedagógica diferenciada que possam auxiliar e facilitar a aprendizagem.

Partindo desse mesmo pressuposto, Mazzotta considera a educação especial como:

[...] a modalidade de ensino que se caracteriza por um conjunto de recursos e serviços educacionais especiais organizados para apoiar, suplementar e, em alguns casos, substituir os serviços educacionais comuns, de modo a garantir a educação formal dos educandos que apresentem necessidades educacionais muito diferentes 
das da maioria das crianças e jovens. Tais educandos [...] têm sido chamados de 'alunos com necessidades educacionais especiais'. (MAZZOTTA, 1999, p. 11).

De acordo com a Política de Educação Especial do estado de Santa Catarina é de responsabilidade do Estado assegurar o AEE, o qual deve acontecer no turno inverso do ensino regular e tem como características: apoio aos alunos com deficiência, possibilitar a eles o aprendizado escolar por meio de atividades diferenciadas das do ensino regular e utilizar procedimentos e instrumentos específicos a fim de facilitar o processo de aprendizagem dos estudantes com necessidades educacionais especiais, sendo estes: alunos com deficiência, condutas típicas e/ou altas habilidades. (SANTA CATARINA, 2009).

As Diretrizes Curriculares Municipais para a Educação Básica de Blumenau (2012) apresenta uma subseção intitulada: Educação Especial.

Esse documento é o norteador dos alunos e professores da educação especial na educação básica do município. O AEE visa acolher os alunos com deficiência, transtornos globais de desenvolvimento e/ou altas habilidades/superdotação, a fim de incluí-los nos espaços da escola regular, oferecendo tal atendimento nas SRM e/ou o Professor de Apoio Pedagógico $(\mathrm{PAP})^{2}$ para perfazer seu direito à educação. (BLUMENAU, 2012)

Complementando a ideia destacada anteriormente acerca da educação especial Meletti e Bueno (2011, p. 369) afirmam que:

[...] a educação especial passa a ser identificada como uma modalidade de educaçáo escolar a ser oferecida preferencialmente na rede regular de ensino, a partir da educaçáo infantil, e apenas nos casos excepcionais em que a escola não tiver recursos, o atendimento de alunos com maior comprometimento poderá ocorrer em instâncias consideradas especiais: classes ou escolas.

A partir da Lei no 9394/96 a educaçáo especial tornou-se uma modalidade de ensino e as suas políticas voltaram-se à inclusão desses alunos nas classes comuns, direcionando seu atendimento à rede regular de ensino.

No que diz respeito ao município de Blumenau suas Diretrizes Curriculares Municipais para a Educação Básica consideram que:

[...] seja respeitada a individualidade dos sujeitos. Para que [a inclusão] ocorra efetivamente se faz necessária uma reformulação da prática e do currículo escolar, pensando em um novo tempo institucional. Portanto, é necessário intensificar a formação dos profissionais da educação (professores, educadores, suporte pedagógico, corpo administrativo, zeladores, cozinheiras, auxiliares de serviços gerais), conscientizando a comunidade escolar para que a prática inclusiva ocorra espontaneamente. (BLUMENAU, 2012, p. 48)

Desse modo, vê-se que não somente os professores, mas todos os funcionários da escola devem se mobilizar para fazerem seu trabalho da melhor maneira possível, adquirindo os conhecimentos necessários para saber lidar com o estudante públi- 
co-alvo da educação especial, pois, conforme Garcia (s.d. p. 12) "[...] é preciso fazer da 'inclusão' uma responsabilidade de toda a sociedade." Cabendo assim, ao Estado e aos órgãos responsáveis pela educação ofertar cursos de formação continuada aos profissionais responsáveis pelo atendimento aos alunos com NEE, viabilizando seu papel com vistas à inclusão. Ainda para Glat e Blanco (2007) uma escola inclusiva requer uma revisão das formas de interação, revendo a formação dos professores e de toda a equipe de gestão, transformando desde seu projeto político pedagógico até suas práticas avaliativas. Ao agir assim a escola tende a desenvolver a inclusão social.

Neste sentido, Glat (2007) pontua que o novo paradigma da Educação Inclusiva traz como consequência um repensar de objetivos e de práticas da Educação Especial, tendo como espaço de atuação a escola comum, mantendo a especificidade do campo de saber, por esta razáo ela considera que a Educação Inclusiva na contemporaneidade é uma questão atual da Educação Especial.

\section{Educação especial na perspectiva inclusiva}

\section{Os sujeitos da educação especial}

No Brasil, em se tratando de educação especial e inclusiva, existe uma preocupação com a aprovação, execução e divulgação das leis, decretos, resoluçôes, e isto vem a comprovar que estamos buscando caminhos que nos levem rumo a um desenvolvimento de nossa política inclusiva.

Ao analisarmos as políticas nacionais, estaduais e municipais destacamos o item: "sujeitos da educação especial" para ser abordado nas respectivas legislaçôes, buscamos ainda destacar estes sujeitos em duas diferentes perspectivas: a educação especial e a educação inclusiva. A análise dos dados se desenvolveu da seguinte forma, buscando o público-alvo dentro de cada política observada.

A Política Nacional de Educação Especial na Perspectiva da Educação Inclusiva aponta como público alvo de educação especial, "[...] os alunos com deficiência, transtornos globais de desenvolvimento e altas habilidades/superdotação." (BRASIL, 2008)

Já na Política de Educação Especial do Estado de Santa Catarina, elaborada pela Fundação Catarinense de Educação Especial - FCEE de 2006 e atualizada em $2009^{3}$, o público alvo da educação especialsão "os educandos considerados [...] diagnosticados com deficiência, com condutas típicas e com altas habilidades." (SANTA CATARINA, 2009, p. 23).

Finalmente em Blumenau, no documento elaborado pela Secretaria Municipal de Educação - SEMED de 2012, o público alvo da educação especial são:

[...] Pessoas com deficiência: aqueles que têm impedimentos de longo prazo, de natureza física, intelectual, mental ou sensorial. Pessoas com transtornos globais do desenvolvimento: aqueles que apresentam um quadro de alteraçóes no desenvolvimento neuropsicomotor, comprometimento nas relaçóes sociais, na comunicação ou estereotipias motoras. Inclui-se nesta definição alunos com 
autismo clássico, síndrome de Asperger, síndrome de Rett, transtorno desintegrativo da infância (psicoses) e transtornos invasivos sem outra especificaçáo. Pessoas com altas habilidades/superdotação: demonstram potencial elevado e grande envolvimento com as áreas do conhecimento humano, isoladas ou combinadas: intelectual, liderança, psicomotora, artes e criatividade. (BLUMENAU, 2012, p. 50).

O que podemos observar é que existe uma diferença considerável na especificação do público alvo entre as políticas aqui apresentadas. Durante a releitura das leis encontramos dados e informaçóes somente no que se refere ao público alvo da educação especial e nenhum registro quando se trata de público alvo da educação inclusiva.

Outro ponto importante a destacar é que na política nacional e na política estadual o público alvo é apresentado, utilizando termos mais amplos como: alunos com deficiência, transtornos globais de desenvolvimento, condutas típicas e altas habilidades/superdotação. Já a política municipal, além de nomear as deficiências, apresenta uma breve definição sobre elas, dando a impressão de afunilamento.

Assim, dentro das políticas nacionais e estaduais observa-se uma maior abrangência dos sujeitos atendidos. Em contrapartida, na política municipal, tem-se a impressão de que o município se propóe a oferecer o atendimento aos sujeitos que se amoldam no que está especificado na política, dando o direito de atendimento somente aos estudantes que se ajustam dentro dessas especificações.

\section{Os serviços de atendimento educacional especializado}

Buscou-se saber quais os serviços disponibilizados ao AEE, como: lugares em que tal atendimento acontece, modo de funcionamento e, se é complementar e/ ou suplementar à escolarização dos estudantes Público Alvo da Educação Especial (PAEE).

Atuar em conjunto com o ensino comum, complementando e/ou suplementando o aprendizado dos alunos PAEE é o que evidencia a Educaçáo Especial na Perspectiva da Educação Inclusiva (2008), mencionando que a:

educação especial atua de forma articulada com o ensino comum, orientando para o atendimento desses estudantes. [...] [o atendimento educacional especializado] complementa e/ou suplementa a formaçáo dos estudantes com vistas à autonomia e independência na escola e fora delas. (BRASIL, 2008, p. 11).

Ainda no documento em âmbito nacional acerca do serviço de AEE, está explicitado que "deve ser realizado no turno inverso ao da classe comum, na própria escola ou centro especializado que realize esse serviço educacional." (BRASIL, 2008, p. 12).

O AEE está centrado nas salas de recursos multifuncionais, indicando assim como e onde ocorre a escolarização dos alunos que apresentam NEE, ou seja, em escolas regulares públicas, nas classes comuns com o AEE acontecendo no contra turno. (MELETTI; RIBEIRO, 2014). 
Ao se tratar dos serviços de AEE, a Política de Educação Especial do Estado de Santa Catarina menciona que "os atendimentos, em educação especial, direcionados aos educandos da rede regular de ensino, teráo caráter de apoio, complemento ou suplemento ${ }^{4}$. (SANTA CATARINA, 2009, p. 27).

Encontra-se ainda nesse mesmo documento, que esses atendimentos podem ser denominados como: Serviço de Atendimento Educacional Especializado - SAEDE; Serviço de Atendimento Especializado - SAESP; turma Bilíngue - LIBRAS/ Português; professor intérprete; instrutor de LIBRAS; professor de educação especial nas turmas de todas as etapas e modalidades da educaçáo básica em que estiverem matriculados alunos diagnosticados com condutas típicas ou severos comprometimentos motores. Dentre os atendimentos, há também os que estão mais voltados à saúde dos educandos PAEE, tais como: acompanhante terapêutico e técnico da área da saúde nas escolas onde têm alunos com deficiência matriculados. (SANTA CATARINA, 2009)

Já no documento estadual de Santa Catarina, intitulado Programa Pedagógico (2009), consta que:

O Estado instituiu o segundo professor de turma nas escolas da rede regular de ensino que tenham matrículas de alunos da educação especial, que por seu conhecimento é um corregente nas turmas de séries iniciais do ensino fundamental e colaborador do professor nas séries finais do ensino fundamental e do ensino médio. (SANTA CATARINA, 2009, p. 16).

Todas as escolas estaduais de Santa Catarina têm um segundo professor nas classes em que os alunos PAEE frequentam, porém, há municípios que não aderiram tal lei, e suas escolas não possuem a presença de dois professores na classe comum, caso esta tenha alunos com deficiência. Já nas que possuem, a nomenclatura varia dependendo do município, podendo esse professor ser chamado de Professor dois, segundo professor, professor auxiliar, professor de apoio pedagógico, entre outros.

Tratando mais especificamente dos serviços disponibilizados aos alunos com NEE de Blumenau/SC, temos as Diretrizes Curriculares desse município, a qual menciona que:

Atualmente [...] os alunos com deficiência do ensino fundamental são atendidos nas salas de recursos multifuncionais instaladas nas escolas; os alunos com surdez e da educação infantil (estimulação essencial) são atendidos no Centro Municipal de Educação Alternativa (CEMEA). Seguindo as diretrizes operacionais do AEE, as salas de recursos multifuncionais e o CEMEA atendem alunos da rede municipal, estadual e particular. (BLUMENAU, 2012, p. 56-57).

Ainda, com vistas à inclusão dos alunos com deficiência, transtornos globais de desenvolvimento e altas habilidades/superdotação, está instituído nas Diretrizes Curriculares de Blumenau a "contratação de um profissional chamado de Professor(a) de Apoio Pedagógico (PAP). Este profissional, juntamente com o professor do AEE, 
atua como suporte da inclusão aos profissionais da escola." (BLUMENAU, 2012, p. 53). O PAP atua na sala comum em que há aluno com NEE, havendo trocas de papéis entre ele e o professor regente, já que o primeiro não deve ser considerado o professor do estudante com NEE, mas de toda a turma, prestando auxílio ao professor regente durante todo o período em que permanecer em sala.

\section{Considerações finais}

No decorrer da pesquisa, foram encontrados alguns desafios, principalmente no que se refere aos conceitos e às relaçóes que são estabelecidas dentro da educação especial na perspectiva da educaçáo inclusiva. O objetivo foi analisar os conceitos e relaçóes estabelecidas entre educação especial e educaçáo inclusiva nas políticas educacionais nas esferas nacional, estadual em Santa Catarina e municipal de Blumenau.

Observou-se que a Política Nacional de Educação Especial na Perspectiva da Educação Inclusiva (2008) é responsável por acompanhar os avanços do conhecimento, visando constituir políticas públicas promotoras de uma educação de qualidade para todos os estudantes.

Já a Política de Educação Especial do estado de Santa Catarina se fundamenta na política nacional para elaborar seus conceitos. Neste documento são atribuídas todas as açóes das escolas da rede estadual de ensino no que tange à educaçấo inclusiva.

A política municipal de Blumenau utiliza definiçôes de documentos internacionais como a Declaraçấo de Salamanca para fundamentar seus conceitos. Nela encontra-se documentos referentes à rede municipal de ensino que é responsável pela educaçáo básica na perspectiva da educação inclusiva do referido município.

Em se tratando de educação inclusiva é possível observar que toda a comunidade escolar, tal como os professores, gestores, demais funcionários e familiares, devem estar envolvidos com um objetivo em comum: incluir os alunos com NEE no ensino regular, oferecendo-os uma educação de qualidade e assegurando sua matrícula, permanência, participação e aprendizagem durante o processo de escolarização.

Quanto à educação especial sua função é disponibilizar instrumentos que ofereçam suporte e apoio para os estudantes com deficiência, transtornos globais de desenvolvimento e altas habilidades/superdotação, por meio do AEE, para que o processo de inclusáo possa de fato acontecer.

\section{Referências}

BLUMENAU. Diretrizes Curriculares Municipais para a Educaçáo Básica, v. 2. Blumenau, 2012.

BRASIL. Diretrizes Curriculares Nacionais Gerais para a Educaçáo Básica: diversidade e inclusão. Brasília, 2013.

Diretrizes Operacionais do Atendimento Educacional Especializado na Educaçáo Básica, modalidade Educação Especial. Brasília, 2009.

Lei no 13.146 de 06 de julho de 2015. Institui a Lei Brasileira de Inclusão da Pessoa com Deficiência. Brasília, 2015.

Lei no 9394/96 de 20 de dezembro de 1996, que institui as Diretrizes e Bases da Educação Nacional - LDBEN. Brasília, 1996. 
BRASIL. Ministério da Educação. Conselho Nacional de Educaçẫo. Câmara de Educaçâo Básica. Resoluçáo no 4 de 2009. Institui Diretrizes para o Atendimento Educacional Especializado na Educação Básica, modalidade Educação Especial.

Ministério da Educação. Decreto n 6.571, de 17 de setembro de 2008. MEC, SEEP, 2008.

. Ministério da Educaçáo. Decreto no 6949de 25 de agosto de 2009. Convenção internacional sobre os direitos das pessoas com deficiência. Brasília, 2009.

Ministério da Educação. Diretrizes Nacionais para a Educaçâo Especial na Educaçáo Básica. Brasília: MEC/SEESP, 2001. 2008.

Política Nacional de Educaçáo Especial na Perspectiva da Educaçáo Inclusiva - MEC/SECADI,

Presidência da República. Casa Civil. Subchefia para Assuntos Jurídicos. Decreto presidencial no 7.611 de 17 de novembro de 2011. Dispóe sobre a educação especial, o atendimento educacional especializado e dá outras providências.

CONFERÊNCIA Mundial de Educação para Todos. Declaraçáo Mundial de Educaçáo para Todos. Plano de Ação para Satisfazer as Necessidades Básicas de Aprendizagem. Brasília, DF: UNIFEC, 1990.

GARCIA, R. M. C. Política de educação especial na perspectiva inclusiva e a formação docente no Brasil. Rev. Bras. Educ., Rio de Janeiro, 18 (52), 101-239, s.d. Disponível em: http:॥dx.doi.org $110.1590 \backslash S 1413$ 24782013000100007. Acesso em 13/11/2015.

GLAT, R. Educaçáo Inclusiva: cultura e cotidiano escolar. Rio de Janeiro: 7Letras, 2007.

GLAT, R.; BLANCO, L. de M. V. Educaçâo Especial no contexto de uma Educação Inclusiva. In:GLAT, R. (org.). Educaçáo Inclusiva: cultura e cotidiano escolar. Rio de Janeiro: 7Letras, 2007.

GLAT, R.; PLETSCH. M. D.; FONTES. R. de S. Educaçáo Inclusiva e educaçáo especial: propostas que se complementam no contexto da escola aberta à diversidade. Educaçáo, Santa Maria, v. 32, n. 2, p. 343-356, 2007.

HOSTINS, R. C. L.; JORDÃO. S. G. F. Política de Inclusão Escolar e Práticas Curriculares: estratégias pedagógicas para elaboração conceitual de público alvo de educação especial. Dossiê: Educaçáo Especial: diferenças, currículo e processo de ensino e aprendizagem II, v. 23, n. 28.

MAZZOTTA, M. J. S. Educaçáo Especial no Brasil: história e políticas públicas. São Paulo: Cortez, 1999.

MELETTI, S. M. F.; BUENO. J. G. S. O Impacto das Políticas Públicas de Escolarizaçáo de Alunos com Deficiência: uma análise dos indicadores sociais do Brasil. Linhas Críticas, Brasília, v. 17, n. 33, p. 367-383, 2011.

MELETTI, S. M. F.; RIBEIRO, K. Indicadores educacionais sobre a educação especial no Brasil. Cadernos CEDES, v. 34, n. 93, p. 175-189, mai./ago. 2014.

MENDES, E. G. A Radicalização do Debate sobre Inclusão Escolar no Brasil. Revista Brasileira de Educaçáo, v. 11, n. 33, p. 387-559, 2006.

Breve histórico da educação especial no Brasil. Revista Educación y Pedagogía, v. 22, n. 57, p. 93-109, mai./ago. 2010.

SANTA CATARINA. Fundaçáo Catarinense de Educação Especial: Programa Pedagógico. São José: FCEE, 2009.

Política de Educaçáo Especial do Estado de Santa Catarina, São José: FCEE, 2009.

SAWAIA, B. As Artimanhas da Exclusão: análise psicossocial e ética da desigualdade social. Petrópolis: vozes, 2001.

\section{Notas}

${ }^{1}$ Outras necessidades educacionais especiais, tais como: transtornos globais de desenvolvimento e altas habilidades/ superdotação.

2 Profissional que contribui no processo inclusivo juntamente com o professor do Atendimento Educacional Especializado, com o propósito de atuar no auxílio aos demais profissionais da comunidade escolar no que diz respeito à inclusẫo desses alunos. 
${ }^{3}$ A atualizaçấo da Política de Educação Especial do Estado de Santa Catarina em 2009 deve-se à adequação à Política Nacional de Educação Especial na Perspectiva da Educação Inclusiva, publicada em 2008.

${ }^{4}$ Complementar: complementar o currículo, viabilizando o acesso à base nacional comum, segundo a LDBEN. Suplementar: ampliar, profundar ou enriquecer o currículo da base nacional comum, segundo a LDBEN. (SANTA CATARINA, 2009, p. 15-16)

\section{Correspondência}

Rita Buzzi Rausch - Fundação Universidade Regional de Blumenau. Rua Antônio da Veiga, 146 - Vila Nova. CEP: 89000-140 - Blumenau, Santa Catarina, Brasil.

E-mail: julymf_sjb@hotmail.com - alinevarelamayr@gmail.com - wuoandrea@gmail.com - ritabuzzirausch@ gmail.com

Recebido em 27 de abril de 2016

Aprovado em 26 de outubro de 2016 